\title{
EARLY SCHOOL LEADERSHIP CHALLENGES IN KAZAKHSTANI EDUCATIONAL MANAGEMENT
}

\author{
Anar Mukhtarova, Turar Ryskulov Kazakh Economic University, anar_mukhtarova@mail.ru
}

The importance of the school leadership has increased significantly in the last decades. Leadership, especially effectiveness of the principal may play a key role in the success and sustainability of a school. The aim of this study was to identify the first year principalship challenges in the comprehensive schools of Kazakhstan. The small-scale study conducted in 2011 utilized a blend of qualitative and quantitative methodology approach with mixed-method techniques: the questionnaire and the semi-structured interview. The total number of the participants was 49 (43 questionnaire respondents and 6 interviewees); representatives of rural, suburban and urban schools. While some key findings of the study replicated previous research results, some other findings were indicated as unique to the Kazakhstani context. Specifically, the need for prior and after appointment trainings, especially in budget and finance areas, allocation of teaching hours among the staff and changing parental attitude towards the schooling were the most challenging issues of the principals in their first year of headship. The perceived gap between the government's desires to integrate into the global educational arena and the schooling status quo demands rethinking and reviewing the current school leadership development. Although the findings are based on a limited sample, there is persuasive evidence for the necessity of a new systematic and strategic approach to the school leaders' preparation and training which will take into account values of the post-soviet Kazakhstan people and needs of a modernized world.

JEL Classification Number: I20, DOI: 10.12955/cbup.2013.18

Key words: challenges, leadership, principalship, Kazakhstan

\section{Introduction}

The subject of early headship including its challenges has been studied by many Anglo-Western scholars. Specifically, while some authors studied the phases of leadership development (Day \& Bakioglu, 1996; Gronn, 1999; Weindling, 1999; Ribbins, 2003) others contributed to the study of beginning principalship challenges. The previous research on the challenges of early principalship indicated that new heads encounter difficulties with socialisation (Greenfield, 1985; Daresh \& Playko, 1994; Daresh \& Arrowsmith, 2003), i.e. adoption of patterns of an organisation and its cultural peculiarities. Precisely, Hobson et al. (2003), Weindling (2000), Bush \& Aduro (2006), Cowie \& Crawford (2008) and others contributed to the identification of the obstacles of the beginning heads and considered implications for further research as well as professional development of principals.

However, the majority of published papers represent studies of English speaking countries, predominantly developed ones. Therefore, the present study attempts to contribute to the number of limited papers about developing countries, particularly, the post-Soviet republics. The present small- 
scale study aims to identify the challenges that principals encounter during their first year of principalship in Kazakhstani comprehensive schools.

\section{Literature review}

While it is nearly unknown which practices the novice principals prioritize in Kazakhstan, Day et al. (2011) claim that, the early phase successful leaders from the project IMPACT prioritized 'to improve physical environment; create supportive, positive climate for teaching and learning; set, communicate and implement school-wide standards' (p.233).

Becoming successful in the early phase may be quite difficult since they are expected to 'sink' or 'swim' on their own (Sackney \& Walker, 2006). Importantly, the first year of principalship can be considered as a continuous learning and 'ongoing process of socialization' (Duke, 1987). Hence, those who 'swim' skillfully are likely to become successful.

There are some researches dedicated to the challenges of the beginning principalship. Despite the fact that they all have different methodological approaches they have similar findings regarding the challenges of an early headship.

Among the largest studies conducted in English speaking countries a significant place is taken by the study of Hobson et al. (2003) entitled 'Issues for Early Headship - Problems and Support Strategies'. This study summarized challenges of newly appointed principals in the UK, the USA and other European countries. As a result Hobson et al. (2003) identified the following issues:

- feelings of professional isolation and loneliness,

- dealing with the legacy, practice and style of the previous headteacher,

- dealing with multiple tasks, managing time and priorities,

- managing the school budget,

- dealing with (e.g. supporting, warning, dismissing) ineffective staff,

- implementing new government initiatives, notably new curricula or school improvement projects,

- problems with school buildings and site management.

Some similar findings were presented by Weindling (2000) in England. This study identified problems connected with interpersonal issues with the staff, especially dealing with staff in terms of low morale and incompetence. Therefore, the research shows that beginning principals have problems with improving the school image and especially with the practices and styles of their predecessors.

A range of concerns with parents, single parent issues, supporting staff in difficult situations and external inspections was identified by Cowie \& Crawford (2008) in Scotland. All these findings suggest that the problems in early headship are serious enough since they affect the efficiency of a leader's performance. Apart from scholars mentioned above, the acting principals are also contributing the exploration of beginning headship challenges. For instance, an Australian principal Terry Quong (2006), studied the experiences of six beginning principals and their correlation with his own challenges. He concluded that they all faced problems in improving student behaviour, conflicting with staff, dealing with parents complaints and critical incidents, improving results in literacy and numeracy and attendance issues. 
A similar reflective paper was published by Ismailova (2011) in Kazakhstan. A novice head of the educational organization explores how to deal with the representatives of different generations, particularly with parents and colleagues. According to her view, the difficulties in dealing with different people could be smoothened if the principal approaches the situation through the value lenses of other people. Therefore, she gives some practicalities of exploring the predecessor's practices. She suggests learning the previous head's best practices and confronting less productive and negative ones. This implies that the leader should have analytical and critical thinking abilities from the first days of headship.

The study findings by Slater, Garcia and Gorosave (2008) in Mexico replicated the findings of the researchers in English speaking countries with regard to paperwork because of bureaucracy, cultural, political and human conflicts.

The contribution of American and Canadian researchers (Greenfield, 1985; Daresh \& Playko, 1994; Crow, 2006; Sackney \& Walker, 2006; Nelson et al., 2008; Sherman, 2008) to this issue is also significant. Particularly, Daresh \& Playko (1994), Crow (2006), Nelson, Colinaand \& Boone (2008) identified difficulties that the socialization process causes for the new principal. For example, Nelson et al. (2008) concluded that vital knowledge for new principals includes technical information and human-relational side of leadership. This implies that new leaders should be prepared to take a new role and be aware of personal and professional vulnerabilities if they lack knowledge and skills. Therefore, preparation of leaders should also promote how to ingrain resilience and moral stamina to achieve success.

However, in order to give a comprehensive picture of the challenges that new principals face in many countries there is a necessity of 'greater international cooperation and insight' (Walker \& Qian, 2006). It is noticeable that the majority of published papers represent studies of English speaking countries, predominantly developed ones. Therefore, the present study attempts to contribute to the number of limited papers about developing countries, particularly, the post-Soviet republics.

\section{Data and methodology}

The overall participants of the study were 6 interviewees and 43 questionnaire respondents. The total return rate of the questionnaire was 57 but 12 of the questionnaire responses were excluded due to the incorrespondence of a school type (since study aimed to involve only comprehensive school principals) and 2 comprehensive school principals' replies omitted 12 items in each questionnaire. Among the questionnaire participants there were 23 male and 20 female participants with mean age 47 (age varied from 33 to 62) from 27 rural, 12 urban and 4 suburban schools. The majority of the respondents were rural principals and it can be explained by the fact that nearly $70 \%$ of all comprehensive schools in Kazakhstan are in rural areas (The Ministry of Education and Science of the Republic of Kazakhstan, 2010).

Basically, the aim of this study was to identify challenges of the first year of school principalship in the comprehensive schools of Kazakhstan. It employed a mixed-method technique and involved 49 practising comprehensive school principals of which six were interviewed. The qualitative approach aimed to seek the meaning and understanding of different aspects of a principalship position. Especially, why and what causes challenges in the first year of school headship. The quantitative approach, which is quite structured, affords an opportunity to gain numerical measurements and establish common patterns. The mixed-method approach has become more frequently utilized by 
researchers in order to give a more generalized overview of a study. The combination of both methods may compensate some weaknesses of each of them (Punch, 2009). Thus, the study combined questionnaire and semi-structured interviews with practicing school principals.

\section{Results and Discussion}

According to the small-scale study results, the main issues that were indicated as challenging in the first year headship in the comprehensive schools of Kazakhstan can be subdivided into internal and external obstacles. Among the external challenges there are such issues as working with inspectors, external demands and pressures, dealing with the parents and changing their attitudes towards the schooling. The internal issues are communicating with staff, dealing with incompetent staff members and staffing issues in general. On a higher system level there are shortcomings in terms of poor prior and after appointment training and support especially in budget and finance areas, lack of finance and poor material-technical facilities of the schools (e.g. lack of equipment, school building repairing).

The key findings of this study reflect some findings of previous researchers. Despite the research background being a developing country, some findings replicated results of studies in developed countries. Taking into account the challenges encountered by the principals in the first year of headship the majority of them $(\mathrm{N}=35)$ indicated that they have changed personally as well professionally. While one principal asserted that it is impossible to adapt to a new environment within a year, another 13 principals did not notice any changes in themselves.

The influence of the newly taken role on whole varied from principal to principal. The major personal and managerial positive changes found as a result of this study. 18 principals out of 49 indicated improvements in communicating and dealing with different staff members, while 11 heads felt a great responsibility in a new role. Further, some principals (9) experienced the practice of self-evaluation and analysis on a new position and 6 leaders assert that improved their skills in setting objectives and achieving them which might be quite logical since 4 began to cope with different tasks that new role demanded from them. Finally, slight changes were perceived in oratorship (2), principals began to speak more confidently and effectively as compared to first days of headship. Building a strong relationship with local community is important especially if the school is located in rural or suburban areas. Thus, this study also shows that 2 principals learnt and built cooperation with other organizations.

According to the changes experienced by principals, presumably, the challenges appear to affect principals' self-efficacy. They become more confident in working relationships and could deal better with the staff $(\mathrm{N}=18)$, could make decisions $(\mathrm{N}=3)$, set goals and achieve them $(\mathrm{N}=11)$. Moreover, this suggests that they may have increased self-efficacy. Two examples illustrate the responses of those who confidently believe in personal efficiency and represent the strategies they employ in daily leadership.

A 50 year old male Principal No 39 with 2 years leadership experience reports: "I learnt some skills of how to plan the management of the pedagogical staff, how to lead the implementation process and monitor. By respecting others I could make them [staff] to meet the requirements I set. I understood that leading is not dictating, it is a big responsibility and you have to believe in yourself".

A 51 year old male Principal No 41 with 3 years leadership experience said: "The leader has many tasks as well as great sense of obligation. For example, in some cases you have to be decisive and brave, in other cases you may even need to be strict". Among the interviewees, Principal 1 realized most acutely how the challenges of the first year affected his personal and professional identity: "as a 
leader of a state organization and from a human perspective I learnt lessons, I improved myself. Therefore, I think those challenges positively influenced my further work and leadership abilities“.

Identity is dynamic; socializing with different people and sense of being a leader and experiencing the role can gradually change it. Importantly, pupils can also contribute to the formation of the leaders' professional identity. As Principal 3 reports, leaders should be able to communicate with children. The perception of being respected by children increases self-efficacy which in turn influences one's perception of the professional identity. He says that "positive emotions that children give to you... when they ask how are you or want me to explain something to them that means that I am respected, they are not avoiding me and afraid of me as it was acceptable in the times of Soviet school directors".

The participants' replies show that formation of the principal's professional identity is a kind of professional role management involving adjustment to the contextual circumstances. It is a cognitive process which develops a principal's professional self and skills vital to the position and role. To some extent it seems that the principal asks him/herself who am I as a principal? Therefore, pre-existing professional identity becomes a corner stone for the formation of a new identity.

This study confirms that it is difficult to define identity. What is noticeable is that the formation of professional identity is based on the previous professional skills. Significantly, this study supports the career patterns of new principals established by Parkay \& Hall (1992; cited in Weindling, 1999), namely 'survival, control, stability, educational leadership and professional actualisation'.

Among the interviewees, Principal 1 found himself unprepared to principalship although he had one year of deputy headship experience in a discipline sector. He pointed out the idea that 'being a good specialist [teacher] is not necessarily being a good leader' which to some extent hints that he lacked leadership skills in the beginning and possibly experienced 'survival' stage. On the other hand, correlation of professional identity with personal identity is also evident. Male Principal 5 and female Principal 6 are those whose leadership abilities were ingrained from youth and they are likely to begin their principalship journey with either 'control, stability' or 'educational leadership' stages.

In terms of formal preparation for principalship, the participants who were in positions of deputy headship prior to principalship appointment consider their previous positions as a formal preparation.

The participants of this study reported that 31 principals $(76 \%)$ were in the position of deputy headship, only 8 principals had headship preparations, 7 principals had teaching experience and 3 principals had neither teaching nor deputy headship experience ( 2 were labour union heads and 1 military commissar). This situation implies that the majority of the principals were not prepared adequately for the position of headship and only relied on their career development paths. However, it is also difficult to define to what extent the courses that 8 people took were useful. One of the questionnaire respondents, No 21, shared her experience of attending courses: "I had one year length principalship courses. I spent much time on it. Instead I should have spent more time with the staff".

Despite the similar career path progression, Kazakhstani principals would like to be trained before taking a principalship position. Especially, they are in need of a separate training on financial and auditing issues in a school. Every fifth ( $\mathrm{N}=10$ out of $\mathrm{N}=49)$ principal wants to have programmes on how to deal with school finances, auditing and accounting matters. Thus, the fact that the majority of principals were deputies who were responsible either for curriculum, teaching methods or discipline of pupils cannot substitute for formal preparation. 
Even though their previous positions are based on practical experiences as opposed to formal preparation, presumably, the absence of appropriate pre-appointment training creates difficulties in dealing with external influences such as inspections and parents.

Apart from external challenges, principals primarily experience difficulties within the organization. Difficulties in communicating effectively with the staff members have been found as a concern in many previous studies (Daresh \& Playko, 1994; Weindling, 2000; Crow, 2006; Nelson et al., 2008; Cowie \& Crawford, 2008). Therefore, finding an approach to the staff members in the beginning may become difficult which in turn may significantly complicate the early socialisation of the principal.

Kazakhstani principals state that 'coming to understanding', 'finding a common language with teachers', 'be on the same wavelength', 'to create positive psychological atmosphere' or 'earning trust' were the most challenging problems of half of the principals $(\mathrm{N}=24)$. Moreover, if the principal is appointed from elsewhere, communicating with new staff demands more effort since he/she is being observed and may be compared to the previous head's style and practices of communicating. The present study shows that nearly every fourth leader $(\mathrm{N}=10$ out of $\mathrm{N}=43)$ encounters difficulties caused by the previous head's style and nearly every fifth principal faces difficulties caused by their predecessor's practices ( $\mathrm{N}=8$ out of $\mathrm{N}=43$ ). As Principal 3 reports, her very first challenge was to get the staff and community to accept her, 'the stranger from the city'. This implies that sometimes rural and urban mentality can cause a serious obstacle to mutual understanding. Thus, her socialisation period began with persuading the staff that 'she was one of them'. Owing to her strong communicative skills, the period of adaptation to rural school staff went smoothly and she could 'conquer' the surrounding people with her supportive and benevolent approach. She strongly believes this is the only way of becoming an accepted figure of authority.

Overall, based on the data gathered, the most challenging issues were external inspections, dealing with the parents and their attitudes towards the schooling and communicating with staff, dealing with incompetent staff members and work hour allocations. It could be suggested that proper finance and more systematic approach to selection, preparation and training of school leaders could give more satisfying outcomes. The schools which are led by well-prepared and qualified leaders are likely to establish strong leadership grounds for sustainability. The performance in the first year may influence further professional development of a principal.

\section{Implications}

The key findings and the discussion of the different challenges that comprehensive school principals in Kazakhstan face during their first year of the headship identified some areas to be researched in the future. Therefore, it suggests some implications for the policy and the school leaders.

To help transition period of the heads in their first year to be less challenging and negative it is necessary to provide adequate pre-appointment preparation. The results of this study indicated that being in a deputy headship position and being experienced may not ease some challenges of a new role. The present state of the school principalship preparation in Kazakhstan is fragmented and seems not to reflect actual needs of the leaders. Thus, more research should be done among practicing principals in identifying their needs (e.g. inclusive education leadership, talented/different ability children) and accordingly, build modules of the preparation courses.

By improving the work system and updating the content of professional training programmes and involving principals in different research studies and projects, professional training institutions can build a culture of evidence-based decision making which may lead mutually beneficial outcomes. 
Specifically, as indicated by principals, acute need is felt in the financial and auditing aspects of trainings.

Apart from the preparation, the study suggests to review the criteria for the selection of the future principals. While some principals indicated that they did not have either educational background or experience, others wished to have a transparent and democratic way of selecting the heads. This situation implies the inconsistency of the selection system and incompetence of some authorities who let the schools be led by professionals from different spheres. Presumably, such situations create indignation of staff members and raise difficulties in the socialisation of the principal. Thus, the standards of selection, appointment, preparation and support for the school principals have to be reviewed on a system level.

The other source of a pressure for the beginning leaders is the external inspections. The variety of inspections and frequency of visits may even misbalance an experienced principal. As it was indicated by the research participants, some inspections are considered as irrelevant. Thus, it might be better to combine some inspection criteria of different committees and establish new standards with appropriate timelines. Importantly, the issue of selecting inspectors has to be approached critically. On the other hand, it seems appropriate to develop internal self-evaluation systems in the schools. The self-check and revision activities could help to prepare for the external inspections.

Particular implications could be related to the practices of the beginning or potential principals. Taking into account that the implications of the current study may not be realized in the nearest future, as it demands considerable changes, instead of waiting for government-induced changes, it might be better to suggest to leaders to be more self-reflective and critical.

It is evident that learning about the school leadership is a gradual process which demands effort and commitment. Hence, every potential leader has to question his/her own preparedness to the leadership position and evaluate and address possible vulnerable areas. Specifically, I would encourage leaders to be more active and collaborative in sharing experiences and helping future leaders to overcome challenges more easily.

\section{Conclusion}

This study set out to explore the challenges of the first year comprehensive school principalship in Kazakhstan. While some findings such as external inspections, poor pre- and post-appointment professional trainings, communicating with staff or dealing with parents replicate previous research results, others turned out to be contextually unique. Hence, changing the parental attitude towards the schooling, issues of building maintenance and division of teaching hours among the teachers are only characteristic for the comprehensive school leaders of Kazakhstan.

Perhaps these insights represent the transition period of Kazakhstan from post-Soviet schooling to a more modernized development. Moreover, the research process indicated that while some principals were eager to be a questionnaire respondent, there were a couple who were considering that 'the information in the country should not go beyond it', which evokes an ambiguous feeling. This implies the need of time to build a new research culture and to inform a change of school leadership. Modern Kazakhstan needs open-minded school leaders who can take benefits of the past and create a better future on the basis of current opportunities. Therefore, the lessons of the past and values of the previous system have some advantages. 
The scope of the study was limited by focusing only on the comprehensive schools since the findings of this study only represent the perceptions of comprehensive school leaders. Specifically, the study took into account both 'entry and encounter' or 'taking a hold' stages, i.e. from the first month to 12 months of principalship (Weindling, 1999). Furthermore, mainly, the research relied on retrospective and reflective mode of the participants, which may dull the initial acute feelings and perceptions of a challenging situation. Lack of research culture may also put a limitation on the openness of the principals' replies, especially in the questionnaire.

However, this small-scale study may help a reader to obtain tentative overview of the current comprehensive school leaders in Kazakhstan and the challenges they face in early headship. It can contribute to the limited research in English about Kazakhstani schooling. The results of this research could also be considered by potential school leaders and professional trainees who can apply new strategies to help struggling leaders.

Importantly, the study points out the significance of pre-appointment preparation and support afterwards. Bush (2009) states that 'in many countries, leadership preparation is no longer an optional activity' and possibly, this should also be mandatory in Kazakhstan. An adequate and coherent approach to the preparation and timely support may help raise the confidence of a new leader and possibly help them build stronger a professional identity. The principal's strong sense of professional identity may affect the staff and sheds light on their confidence. Further, the team collaboration builds the school identity and encapsulates unique school culture.

Taking into account the study results and proposed implications, it could be recommended to establish a department and network in the professional training institutions such as 'School of a Young Leader' where new leaders can share problems, exchange ideas and support each other, the primary aim of which could be assigning mentors, giving feedback, teaching of some technical skills and at least help to identify a leader's personal needs and plan self-improvement steps. Hence, these practices may help the leader's transition and encounter stages be less challenging and more positive.

Overall, the elimination of weaknesses of professional training institutions, implementation of changes or the fulfillment of improvements can only be achieved with the systematic reform at the government policy level.

\section{References}

Bush, T. (2009). Leadership development and school improvement: contemporary issues in leadership development. Educational Review, 61 (4), 375-389. doi: 10.1080/00131910903403956

Cowie, M. \& Crawford, M. (2008). Being a new principal in Scotland. Journal of Educational Administration, 46 (6), 676-689. doi: 10.1108/09578230810908271

Crow, G. (2006). Complexity and the beginning principal in the United States: perspectives on socialization. Journal of Educational Administration, 44 (4), 310-325. doi:

$10.1108 / 09578230610674930$

Daresh, J. C. \& Playko, M. A. (1994). Aspiring and practising principals' perceptions of criticals kills for beginning leaders. Journal of Educational Administration, 32 (3), 35-45. doi: $10.1108 / 09578239410063102$

Day, C., Sammons, P., Leithwood, K., Hopkins, D., Gu, Q., Brown, E. \& Ahtaridou, E. (2011). Successful school leadership. Maidenhead, England: Open University Press. 
Duke, D. (1987). School Leadership and Instructional Improvement. New York, NY: Random House.

Greenfield, W. D. (1985). The moral socialisation of school administrations: Informal role learning outcomes. Education Administration Quarterly, 21 (4), 99-119. doi: 10.1177/0013161X85021004007

Hobson, A., Brown, E., Ashby, P., Keys, W., Sharp, C. \& Benefield, P. (2003). Issues of Early Headship-Problems and Support Strategies. Retrieved July 27, 2011, from National College of School Leadership, Nottingham Web site: www.ncls.org.uk

Ismailova, D. M. (2011). Menja naznaczili rukovoditelem [I was appointed as a leader]. Spravocznik rukovoditeljaobrazovateljnovo uczrezhdjenija [Handbook of an educational institution's leader], 6 (54), 77-82.

Nelson, S., Colina, M. G. \& Boone, M. D. (2008). Lifeworld or systemsworld: what guides novice principals? Journal of Educational Administration, 46 (6), 690-701.doi: 10.1108/09578230810908280

Parkay, F. \& Hall, G. (Eds.) (1992). Becoming a Principal. Boston, MA: Allyn and Bacon.

Punch, K. F. (2009). Introduction to Research Methods in Education. London, England: Sage Publications. Retrieved June 30, 2011, from http://www.sagepub.com/upmdata/31987_Punch_Final_Proof.pdf/

Quong, T. (2006). Asking the hard questions: being a beginning principal in Australia. Journal of Educational Administration ,44 (4), 376-388. doi: 10.1108/09578230610676622

Sackney, L. \& Walker, K. (2006). Canadian perspectives on beginning principals: their role in building capacity for learning communities. Journal of Educational Administration, 44 (4), 341-358. doi: $10.1108 / 09578230610676578$

Sherman, A. (2008). Using case studies to visualize success with first year principals. Journal of Educational Administration, 46 (6), 752-761. doi: 10.1108/09578230810908334

Slater, C. L., Garcia, J. M. \& Gorosave, G. L. (2008). Challenges of a successful first-year principal in Mexico. Journal of Educational Administration, 46 (6), 702-714. doi: 10.1108/09578230810908299

The Ministry of Education and Science of the Republic of Kazakhstan (2010). Plan meroprijatij na 2011-2015 gody po realizacii Gosudarstvennoj programmy razvitija obrazovanija Respubliki Kazachstan na 2011-2015 gody I etap [The state programme on educational development for the years 2011-2020 in the Republic of Kazakhstan]. Retrieved April 19, 2013, from www.edu.gov.kz/fileadmin/user_upload/npa/gosprogramma/GPRO_Plan_rus_itog.doc

Walker, A. \& Qian, H. (2006). Beginning principals: balancing at the top of the greasy pole. Journal of Educational Administration, 44 (4), 297-309. doi: 10.1108/09578230610674921

Weindling, D. (1999). Stages of Headship. In Bush, T., Bell, L., Bolam, R., Glatter, R. \& Ribbins, P. (Eds.). Education Management Redefining Theory, Policy and Practice. (p. 90-101). London: Paul Chapman Publishing.

Weindling, D. (2000). Stages of Headship: A Longitudinal Study of the Principalship. Paper presented at the Annual Meeting of the American Educational Research Association New Orleans, LA, April 24-28, 2000. EDRS 451591. 